\title{
An MS-DOS-Based Program for Analyzing Plutonium Gamma-Ray Spectra
}

Volume 2

System Operation, Software Installation, and Maintenance of the Data-Transfer, Data-Analysis, and Quality-Assurance Applications

\author{
W. D. Ruhter
}

W.M. Buckley

Manuscript date: September 7, 1989

\section{LAWRENCE LIVERMORE NATIONAL LABORATORY University of Califomia - Livermore, Califomia - 94551}




\section{Contents}

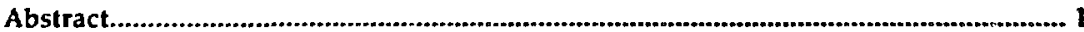

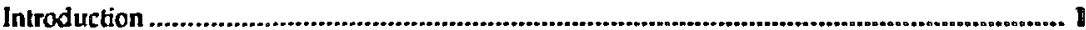

Dala Transfer ......................................................................................................

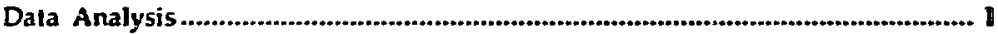

Quality Assurance............................................................................................. 2

Operating Instructions ................................................................................................ 2

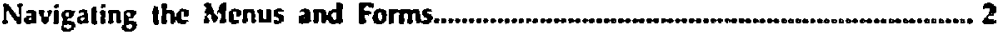

Starting the Program......................................................................................................... 2

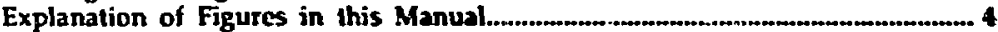

Changing System Defaults............................................................................................... 4

Change Default Abundances........................................................................ 5

Change Batch Sample Information................................................................ 5

Change Default Drive and Path...................................................................... 6

Data Transfer ..............................................................................................6 6

Sample/Spectrum Iniormation Form ............................................................. 7

CICERO Data Transfer Menu............................................................................ 8

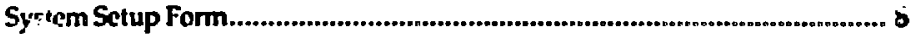

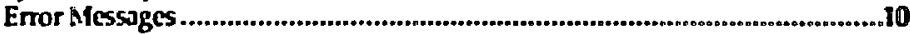

Dala Analysis ............................................................................................................10

Analysis Error Messages......................................................................................15

Output of Dala-Base Records.................................................................18

Quality-Assurance Analysis..........................................................................................18

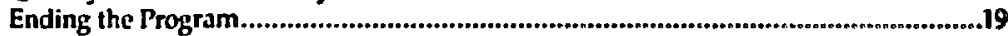

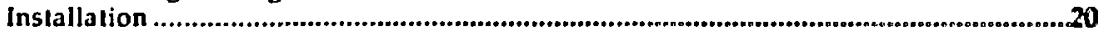

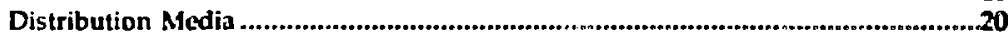

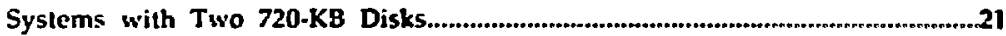

Systems with Hard Disks...........................................................................................21

Maintenance ......................................................................................................................21

To Rebuild IAEA.EXE..............................................................................................22

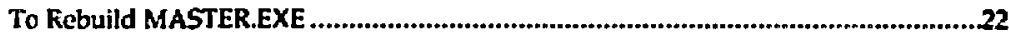

Spectral Data-File Formals....................................................................................22

dBASE III Data Structures .......................................................................................23

Disk File Index ...........................................................................................................30

Batch Files.......................................................................................................30

Information Files...........................................................................................30

Common Files......................................................................................................

Data-Base Files...............................................................................................31

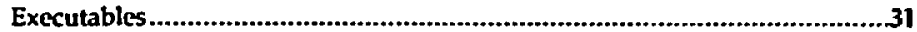

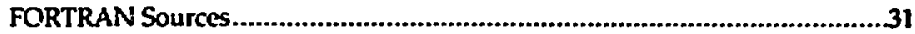

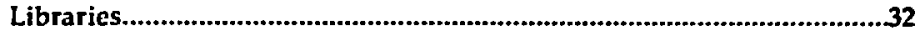

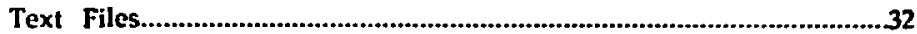

Make Files..............................................................................................32

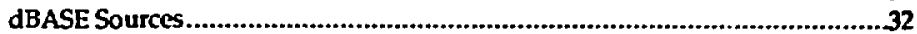

Information Files ..........................................................................................32

Help Window Files.........................................................................................32

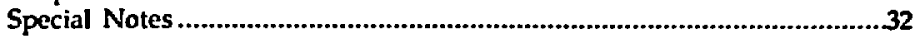

IAEA Routine-Calling Hierarchies .............................................................33

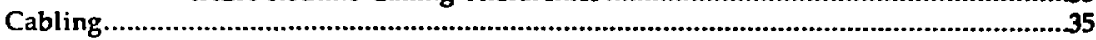

"PC" type cables (for IBM PC/XT and "clones").........................................................35

"AT" type cables (for IBM AT and most "laptops")...................................................35

Acknowledgments ................................................................................................................36 


\title{
An MS-DOS-Based Program for Analyzing Plutonium Gamma-Ray Spectra
}

\author{
Volume 2 \\ System Operation, Software Installation, and \\ Maintenance of the Data-Transfer, Data-Analysis, \\ and Quality-Assurance Applications
}

\begin{abstract}
A plutonium gamma-ray analysis system that operates on MS-DOS-based computers has been developed for the International Atoinic Energy Agency (IAEA) to perform in-field analysis of plutonium gamma-ray spectra for plutonium isotopics. The program titled IAEAPU consists of three separate applications: (1) a data-transfer application for transferring spectral data from a CICERO multichannel analyzer to a binary data file, (2) a data-analysis application to analyze plutonium gamma-ray spectra for plutonium isotopic ratios and weight percents of total plutonum, (3) and a data-quality assurance application to check spectral data for proper data-acquisition setup and performance. Volume 2 describes the operations of these applications and the installation and maintenance of the software.
\end{abstract}

\section{Introduction}

The IAEA Plutonium Isolopics Analysis System is comprised of a Microsoft FORTRAN-7/(c) application, a Clipper(c)-compiled dBASE I!I(c) menu, and a forms front-end program with on-line help implemented using Flashup(c). The tw modules are coordinated by MS-DOS "BAT" procedures and communicate via dBASE III files.

It is intended to help provide a portable, accurate, and automated inspection capability for the International Atomic Energy Agency.

\section{Data Transfer}

This application transfers data from a Silena CICERO 8K multichannel analyzer via an RS. $232 \mathrm{c}$ link and writes a binary spectral data file to disk along with dBASE III compatible descriptive information.

\section{Data Analysis}

This application is an extension of the IAEA "Blue Box" software. It analyzes plutonium gamma-ray spectra for plutonium isotopic ratios and weight percents of total plutonium. The program is 
capable of analyzing gamma-ray spectra of mixed uranium and plutonium saniples for pluterium isotopics and ${ }^{235} \mathrm{U}$ to total plutonium ratio.

The program analyzes gamma-ray peaks beginning at 123 keV up to 363 kelt. For a complete analysis, the spectrum must start at or below $1215 \mathrm{keV}$ and include the 2702020 -keV peak. The only input required for the program are the positions of the 2t1 Ju 148-keV and 270 208-keV peaks. This information is often made available by the dBASE III files written by the data-transfer appiticulon.

\section{Quality Assurance}

This application performs peak-shape analysis on peaks specified and provides the user with full-width-half-maximum values (FWHMI) at 122 and $208 \mathrm{kcV}$. It also examines the high-encrgy side of the high-energy peak for pileup. If it is significant, it wams the usct. It also checks the gain to determine if it is appropriate for plutonium isolopic measurements.

\section{Operating Instructions}

The following instructions assume that the IAEA programs for spectral data transfer, anolysis, and quality-assurance checkıng have been installed according to the insiructions given in the installation section of this document or the README.TXT file.

- The disk files referred to in this document for altemate reading will be found on the PROGRAM diskette.

- Most of the material in this manual can be found in the OPINSTR.TXT fik.

- Responses from the compuler are shown in couriez typeface throughout this document.

- Instructions to press specific keys on the keypad are placed in angle brackets. Some examples are as follows:

$$
\begin{array}{ll}
<A> & \text { press the 'A' key } \\
\text { <esc> } & \text { press the esc (escape) key } \\
\text { <PgDn> } & \text { press the } \mathrm{PgDn} \text { (page down) kcy }
\end{array}
$$

\section{Navigating the Menus and Forms}

Operations are chosen by pressing an appropriate key and then eenters. Each opcration is shown on a menu with the associated key for that operation. To choose an operation, press the indicated key once and <enter>. This will select that operation.

When entering or editing information on a screen, $<\mathrm{PgDn}>$ exits a screen and saves the new information. If you make a mistake and do not want to save the new information, <ese lor alternatively, $<Q>$ (quit) available in most menus] will exit you from that screen and not save the new information.

\section{Starting the Program}

On a floppy-based system (Tioshiba 1100 or 2100 without a hard-disk drive), place the PROGRAM diskette in drive A. If the system prompt is not $\mathrm{A}:>$, then type

$$
\text { A:<enter> }
$$

IA<enter>

Otherwise, just type

$$
\text { IA<enter> }
$$


On a hard-disk-based syslem, simply type

JA<enter $>$

The Title screen (Fig. 1) will appear, followed by the top-level menu (Fig- 2).

\section{IAEA PLutonium Isotopics Analysis}

by

The Iawrence Iivermore National Laboratory

and

Compuchen, Inc.

Version 4.2

July 1989

Written by:

W. Ruhter R. Fleming R. Gunrink W.M. Buckley R. Henning

Figure 1. Tille screen.

IAEA Plutonium Analysis System

88.07.27

$02: 04: 51$

International Atomic Energy Agency

Plutonium Analysis

Menu Options:

T) Transfer Data from Cicero Analyzer

A) Analyze Data from Gama-Ray Spectra on disk

c) Check Quality Assurance

D) Change Default Settings

Q) Quit this menu and return to system Enter Choice: $T$

- 〈Enter the appropriate key or use the arrow keys then press enter>

Figure 2. Top-level menu. 
The top-level menu provides access to all other menus and eptions in the program. The usur may transfer a specirum from the CICERO analyzer by $\langle T\rangle$, analyze spactral dab by $\langle A\rangle$, perform a quality-assurance test on spectral data by $<C>$, change the defauli settings by $<D>$, or exit the program by $<Q>$ or $<e s c>$.

\section{Explanation of Figures in this Manual}

Figures that represent forms in the program hate "pictures" that represent the type of dato that can be entered into a field. A description of these pictures follows:

YY.MM.DD is a date, where

$Y$ is 2 digits for the year

$M M$ is 2 digits for the month

$D D$ is 2 digits for the day:

HH:MM:SS is a time, where

HH is 2 digits for the hour

MM is 2 digits for the minule

SS is 2 digits for the seconds;

9999

is a numeric field 4 digits wide;

$Z Z Z Z Z Z$ is an alphabetic field $(A-Z, a-Z) 6$ characters wide;

Z9Z9Z9 is an alphanumeric field $(A-Z, a-2,0-9) 6$ characters wide.

\section{Changing System Defaults}

The fourth option of the main menu allows the usct to clange default settings (Fig. 3). The plutonium analysis default abundances (Fig. 4) and batch sample information (Fig. 5) can be chaiged, as can the default drive and the path (Fig. 6) where the dala bases can be found.

Plutonium Analysis system

88.07 .27

$02: 04: 51$

\begin{tabular}{|l|}
\hline Change Default Settings \\
\hline A) Change Analysis Defaults \\
D) Change Default Drive and Path \\
E) Exit This Menu \\
Enter Choice: A
\end{tabular}

<Enter the appropriate key or use the arrow keys, then press enter>

Figure 3. Change default settings. 


\section{Change Default Abundances}

For each analysis, a comparison is made beturen the measured isotopic abundances and the declared isotopic abundances, if the latter are provided. Default declaned isotopic abundances may be entered here so that they are used for each subsequent azalysis until changed. The isotopic abundances may also be entered in the Plutonium Abundance form under the Dato Analysis option, but these entrits are overwritten by the default abundances on subsequent analyses.

\begin{tabular}{|c|c|c|c|c|}
\hline \multicolumn{5}{|c|}{ Change Default Mbundances } \\
\hline Pu Analysis Date: & $\cdot$ & An Analy & ysis Date: & \\
\hline \&Pu-238 Abundance: & 0.0000 & $P u-238 \mathrm{~s}$ & A Error: & 0.0000 \\
\hline Pu-238 Abundance: & 0.0000 & $P u-238$ & Error: & 0.0000 \\
\hline Eu-238 Abundance: & 0.0000 & Pu-238 & Erraz: & 0.0000 \\
\hline 8 Pu-238 Abundance: & 0.0000 & Pu-238 & Error: & 0.0000 \\
\hline Pu-238 Abundance: & 0.0000 & Pu-238 & Erraz: & 0.0000 \\
\hline Qu-238 Abundance: & & Pu-238 & Errar: & 0.0000 \\
\hline
\end{tabular}

Type in value $\quad \uparrow, \downarrow$ and $\downarrow$ PgDn
Move Field Cursor Exit Screen Abort Screen

Figure 4. Change default abundances.

Change Batch Sample Information

Default batch sample information may be entered here. This information is used on all subsequent analyses until changed. Batch sample information may also be entered under the Dala A ralysis option, but this information is overwritten by the default information on subsequent analyses.

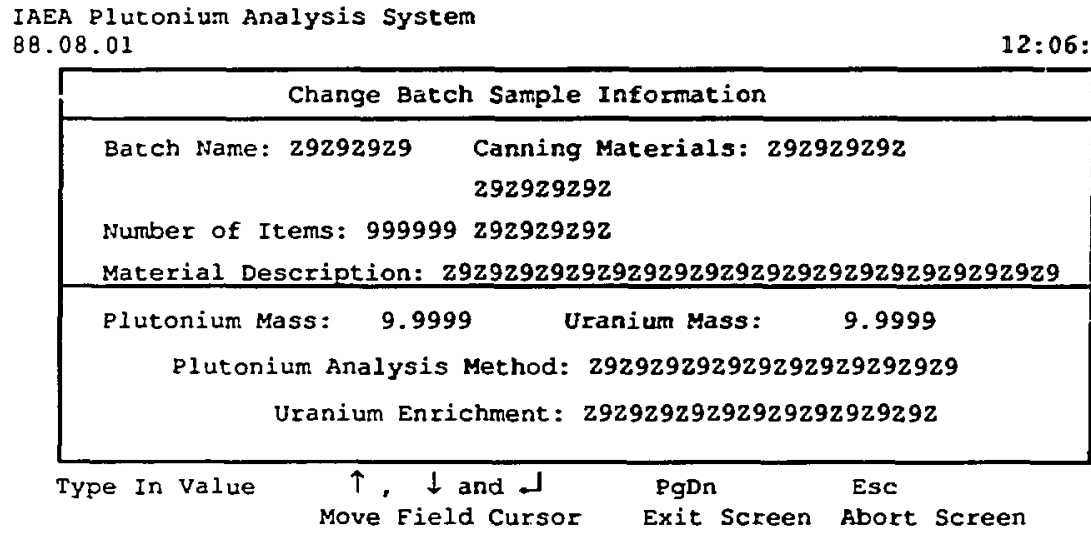

Figure 5. Change batch sample information. 


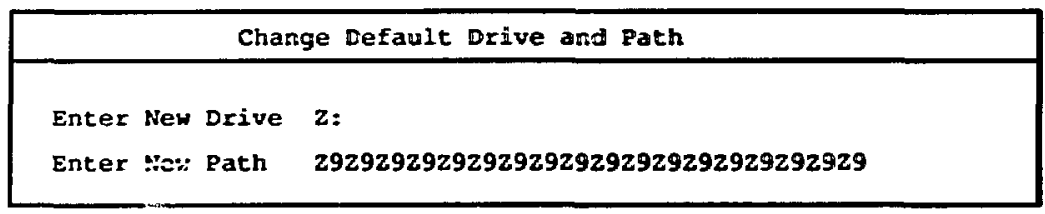

Figure 6. Change default drive and path.

\section{Change Default Drive and Path}

The initial default setting is for the data bases to be found on the root dircetory of drive B. By setting a drive and path for the data bases, the user may put them anywhere on the disk, and the IAEA system will 'ind them. If the data bases ane not where the default drive and path specify, an crror message will be displayed when that data base is needed. The user may then either exit the system and move the data bases to the appropriate subdirectory or change the default drive and path to where the data bases actually are. When entering the defuult drive and path, the uscr must make sure to give a valid drive letter and path. If an invalid drive or path is entered, an crror message will be displayed when the database is needed.

\section{Data Transfer}

To transfer data from a CICERO analyzer to a Toshiba personal computer, a cable must be connected from the COMM port on the compuler (DB-9 connector) to the J2 RS-232c port on the CICERO (DB-25 connector). See the section on cabling for information on the appropriate cable. The model $8500 /$ RSIO interface board for RS-232c communicalions must be set 109600 baud and data format type $A$. For data format type A, swiithes 1 to 3 on the dip 5witch assembly at the rear of the 8500/RS1O board are set to $O N$, and switches 4 and 5 are set to OFF.

Data transfer is initiated by the computer, but before data transfer can occur, the CICERO must be set up for data transfer to the computer. This is dene by pressing the DATA OUT pushbutton on the CICERO and selecting the appropriate options. There are three data-out oplions on the CICERO that must be set correctly for data to be transferred to the computer.

The first option, MEM. RANGE, must be set to the size of the spectrum to be sent. To transfer a 4096-channel spectrum from the first half of the analyzer memory, MEM. RANGE must be set to HALF 1 by $<1>$ on the CICERO numeric keypad, followed by $<2>$ and then $<1>$.

The second option, PERIPHERALS, must be set to COMPUTER. Selecting COMPUTER is done by $<2>$ and then $<4>$ on the CICERO numeric keypad. The OUT. MODE option must be set to TOTAL, which is done by $<3>$ on the keypad, after which TOTAL is displayed.

When the correct DATA OUT options have been selected, the DATA OLT pushbutton is pressed again, followed by the STOP pushbutton. The CICERO is now ready for data transfer to the computer.

To start the data transfer program on the computer, the data transfer option is selected from the top menu option list by <T> on the computer keyboard, followed by <enter>. The Sample/Speclrum Information form (Fig. 7) will appear on the screen. This form contains fields for the sample number, the 148- and 208-keV peak positions, and the spectrum filename. (The drive and pat.. are not required if the data are stored under the default drive and path.) If a drive and path are specified, they will take priority over the default specification.

At the bottom of each form, instructions are displayed to aid the user in completing the fields in the form. In the lower left-hand corner of the screen, a message is displayed, which tells the user whether to "type in value" or to "toggle choice" by <F2>. To move from field to field, the user may use 
the UP or DOWN arrow keys or <enters. Exiting the form is done by <PgDn>, and aborting the form is done by resc>.

IAEA Plutonium Analyis Systen

88.08 .01

$12: \geq 9: 20$

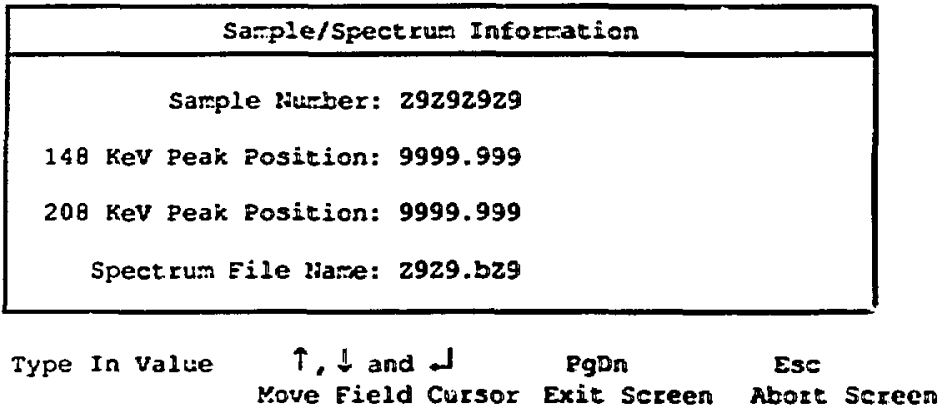

Figure 7. Sample/spectrum information form

\section{Sample/Spectrum Information Form}

The spectum number and peak positions are stored in a dala-base fike along with the spectrum filename. The spectrum filename must be given in order to store the data transferted from the CICERO. When the spectrum filename is entered, the program checks for duplicate fikenames and wams the user if a duplicate filename exists. The user is given the option of writing over the old data file or entering a new filename. When the form is complete, the user may exit the form by <PgDn>. This form is then replaced by the CICERO Dala Transfer menu (Fig. 8).

IAEA P1utonium Analysis System

88.08 .01

$12: 46: 36$

\begin{tabular}{|l|}
\hline Cicero Data Transfer \\
\hline S) System Setup \\
I) Inspection Identification \\
E) File and Peak Information \\
T) Transfer Data from Analyzer \\
A) Abozt Data Entry and Exit \\
Enter Choice: 2
\end{tabular}

Cicero Data Out Instructions

1. Memory Range : Half 1

2. Peripheral : Computer

3. Out. Mode : Tctal

<Enter the appropriate key or use the arrow keys then press enter>

Figure 8. Data-transfer menu. 


\section{CICERO Data Transfer Menu}

The first two options ( $<5>$ and $<\mid>$ ) select other forms that my be filled out to recond information regarding the inspection and the system setup in a data-base file. The third option selerts the form described above.

Only the information requested in the Sample/Spectrum Information form must be previded ter data transfer. The other forms are provided as aids w the user. Once the Sumple/Spectrum Information form is completed, the data transfer is started by <T>, followed by <enters in the menu shown in Fig. 8. The data-transfer option may be aborted at this point by <ese>

\section{System Setup Form}

The system setup form (Fig. 9) represents the front panel of the CICERO amplifiex/ADC, and its purpose is lo record the scttings of the amplificr/ADC. It is NOT necessary, howerer, to fill in this form in order to transfer the spectral dan.

The first time the data-transfer option is selected, dedaule values are displayed in this form These are the values associated with the last spectrum stored. The values are stored in the dala-buse file, MCAPAR, which may be edited wilh the dBASE III(c) program. If you change any of the fields in the form, the new values are kepl until the main conlrol program is exiled $(<Q)$ or <cses in the main option menu).

Thus the form need only be edicd once for a series of measurements, with each having the same amplifier/ADC selup. Some of the fields in this form require typing in a value or comment, while others require using $<F 2>$ to select the value corresponding to the setting on the CICERO analyzer. The required lype of entry is indicated in the lower left-hand cornet of the compuler screen. The user can exit this form, saving new values, by $<\mathrm{PgDn}>$ and can abont the screen, leating the values unchanged, by $<$ esc $>$.

Piutonium analysis System 88.07 .27

$12: 47: \mathbb{1}$

IAEA Plutonium Acquisitien System Setup

\begin{tabular}{|l|}
\hline PUR: 222 \\
BLR Adj : 2222 \\
Shape: 2222 \\
Rate: 2222
\end{tabular}

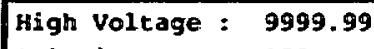

Polarity : 2222

Low-Level Discriminator: 9.99

PZA Adjustment: z9Z9Z9Z9Z9Z929Z92929

Input Switch: $\mathbf{2 2 2 2}$

Shap:ing Time: $\quad 9.99$

\begin{tabular}{|c|c|c|}
\hline \multicolumn{3}{|c|}{--- GAIN $-\cdots$} \\
\hline Coarse & : & 9.99 \\
\hline Fine $A$ & & 9.99 \\
\hline
\end{tabular}

Toggle Choices Move Field Cursor
E2

\section{$\uparrow, \downarrow$ and $\downarrow$}

Figure 9. IAEA Plutonium Acquisition System setup form. 
Default values are initially rad inlo the inspextion Identification form (Fiz. IOH). New. information entered in the form is netsined afler exch spextrum transter until it is changed or untis the main control program is exited. Thus, only an inital setup of the fem is requircd for seriss of measurements in which the Inspertion ID infermation is the sume. The Dute and Time of Mkastifumin! fields, which contain the currert dale and time, are automatically filkd in by the program. The dare and lime information is used to decay-conect the declared isolopic alundances, if giten in the Plutonium Abundance form (Fig. 13), to the lime of the masuremcnt. Mcase move that if the data was acquired at a time and dole other thus the present, then the conect dak and time must ke enterd. $<$ PgDn $>$ exils the form and nclums tixe program to the CKCERO Dats Transfer seincion manu.

IRER Rlutonits Analysis System 88.07 .27

$17: 01: 35$

\begin{tabular}{|c|c|}
\hline \multicolumn{2}{|c|}{ Inspection Idertification } \\
\hline $\begin{array}{l}\text { Countzy Code: zzzzazz } \\
\text { Material aalanze Code: } 292929\end{array}$ & 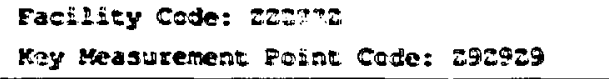 \\
\hline $\begin{array}{l}\text { Inspection Reprze Hurber: } 2929 \\
\text { :ame of Coordisatiny Inspector } \\
\text { Remazks: } \\
\text { 292929292929z229292929292 }\end{array}$ & 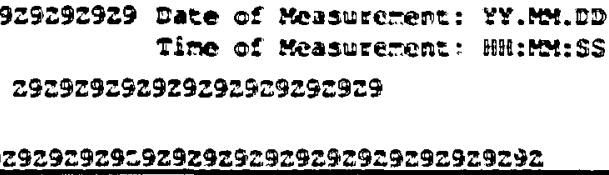 \\
\hline
\end{tabular}

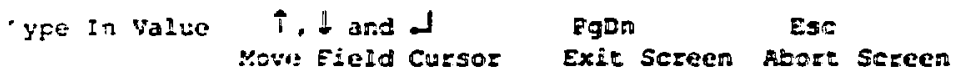

Figure 10. Inspection Idenlification.

While in the CICERO Data Transfer menu, the user starts the transfer of data from the CICERO by $<T>$, followed by <enters. Before slarling the data iransfer, the user sho'sld check to make sure the CICERO Data Out options are set according to the instnuctions at the bottom of the menu. The data will be transferred from Task 1 in the CICERO, regardless of how the Task sclection switch is set on the CICERO. Once crmmunicalions are established between the computer and the CICERO, the following message appears on the screen:

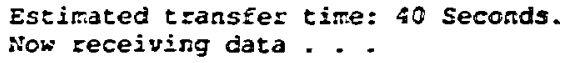

and the DATA OUT pushbutton LED is illuminated on the CICERO. Data transfer takes about 40 s for 4096 channels. When the data transfer is completed, the messages appear on the screen:

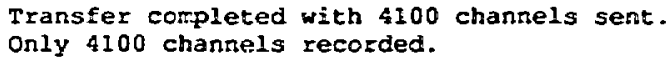

These messages tell the user how many channels of data were sent and warn the user that only $\mathbf{4 1 0 0}$ channels are stored. The current size of the data arrays in the program can accommodate 4100 channels of data. Thus, if an $8 \mathrm{~K}$ spectrum is transferred, only the first half of it is stored. This is followed with the messages

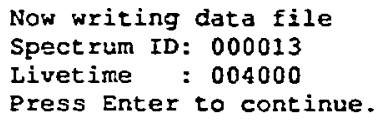


indicatirg that the transferred dala is being writter fo disk. The spectrum ID number assignnd by the CICERO analyzer and the spectrum Jivetime are a!so dispiayed. <Enkrs retums the program to the top-level menu.

\section{Enor Messages}

If there is a problim in communicating with the analyzer, the following messuges will appear on the screen:

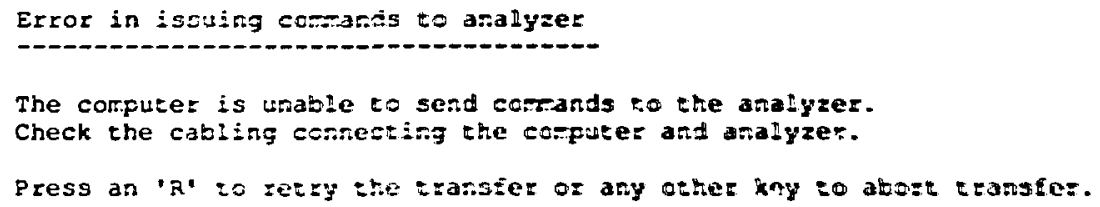

If these messages occur, the user should check to make sure that the corret cable IS CONXECTED between the computer and the analyzer. If there is a probtem with the cable, the user shoukd comext it and try again by $<R>$. If the problem has been corrected, the messige

Now receivisg ba:a

is displayed ainost immediately. If the problem cannol be corrected, typing any key other than an " $R^{\text {"n }}$ will abort the transfor.

\section{Jała Analysis}

The DATA ANALYSIS option is selected from the top-level menu option list by $<A>$, followed by <enter>. The File and Peak Informalion form (Fig. 11) is displayed initially when this option is selected. This form obtains the spectrum filename and the channel positions of the 148-and 208-keV peaks.

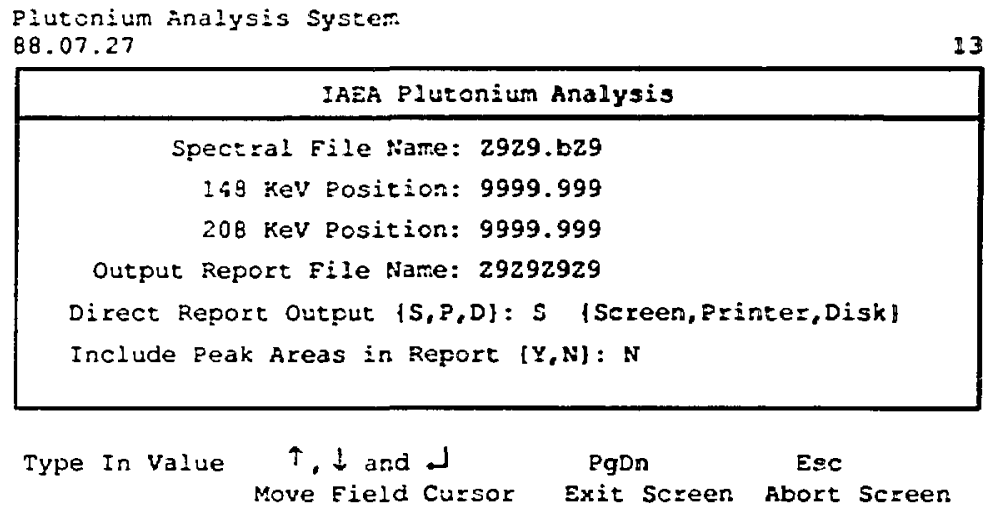

Figure 11. LAEA Plutonium Analysis form. 
After the spectrum filename is entered, the program scarches a data-base fie for the fikmame and, if found, relrieves the 148-and $208-\mathrm{keV}$ peak position information and bouds it into the appropriate fields in the form. If the specirum filename cannot be found in the MCAPARDBF dutabase file, the system searches the IAEA.DBF for the spectnum filename, and if the seareh is unsuccessful, the following message appears at the bottom of the compuke serten:

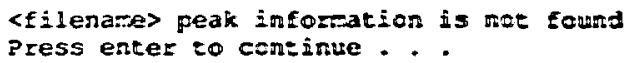

This message wams the user that the peak position information is not available from a data-base file and must be provided by the uscr. Once any kcy is pressed in response to this message. the program relurns to these fietds for completion by the uscr.

The 148- and 208-keV peak position fields must be compleked for an analysis to be done. So that the analysis results can be stored in a data-base fite, the uscr is also asked for a sample number, if the spectrum filename was not found in the data base.

If the analysis output is directed to a disk file, the output report filename is used. If the oulput is directed to a printer or the computer screen, the report fik name is not required. If the spectrum filename starts with "S," then the report filename defaults to a filename starting wilh " $R$," and the remaining characters and file extension are the same as the spectrum filename. The user may change the name of the output report, if desired.

Several options are available for the device to be used for output of the analysis. Initially. a default setting is provided that may be changed by ediling the IADEFALT data-base file. The analysis may be sent to an attached printer by $\langle P>$. It may alsa be sent to the compuler scrien by $\langle S>$ or to the disk by $<D>$. Finally, on this form the uscr has the option of including the peak areas in the analysis report. If the peak aress are not included in the report, the analysis report is contained on one page. The default selting for this option is not (N) to include the peak areas in the report. This furm is exited by $<\operatorname{PgDn}>$ lo save the values, or by <esc $>$ to abott the eniries.

The File and Peak Information form is then replaced by the Plutonium Anoissis menu shown in Fig. 12. This is the only form that must be completed in order to do a spectrum anolysis. The first option selects the form described above (Fig. 11). The $\langle P>$ or $<B>$ options seiect forms that obtain information regarding the sample and store this information into a data-base file.

\section{Plutonium Aralysis System}

88.08 .03

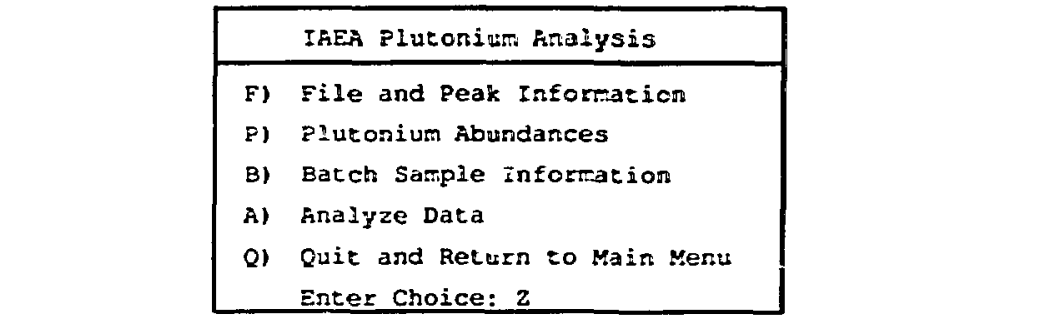

$13: 01: 35$

<Enter the appropriate key or use the arrow keys, then press enter>

Figure 12. IAEA Plutonium Analysis menu.

The Plutonium Abundances form (Fig. 13) is used to obtain the sample's derlared isotopic abundances, their errors, and the plutonium and americium analysis dates. The isotopic abundances and the analysis dates are required only if a compirison between measured and declared isotopic 
abundances (T*2 statistical test) is desired. This form is also used for entering the 24: Pu abundance and its percentage error, if a known value is to be used in calculating the abundances of the other plutonium isotopes. If the ${ }^{242} \mathrm{Pu}$ abundance is set to zero in this form, the ${ }^{22} \mathrm{Tu}$ abundance and its errer ane calculated by the analysis program. Nole: the analysis dates are entered as ycar, month, and duy.

Default values for the isolopic abundances are read from the 1ADEFALT dalabuse file, when the program is first started. NOTE: It is recommended that the default values in the data-buse fike be set to zero, if the user does not intend to use this form for the T*2 statistical test. If isetopic abundances are entered, the values are kept for each subscquent analysis until they are changed or th: main contred program is exited. For the isotopic abundance errors a default value of 10. s is provided only for ${ }^{21 ?} \mathrm{Pu}$. When the Plutonium Abundances form is selected, the user is first queried with

$$
\text { Are the abundances known }(Y, N) \text { ? }
$$

Either <Y> or <enter> will indicate that the abundances are known and the user wishes to enter the values. $<N>$ indicates that the abundances are not known or that it is desired to set all the abundances to zero and have the ${ }^{242} \mathrm{Pu}$ abundance calculated by the program. If $\mathrm{N}$ is cnierzd, the form displays a query for the plutonium cooling time (years) with a default value of 4 years protided. The coaling lime is used in the calculation of the ${ }^{242}$ Pu abundance. If the cooling time is known, the user enters the value in place of the default value.

IAEA Plutonium Aralysis System

88.08 .03

$12: 35: 35$

\begin{tabular}{|c|c|c|c|c|}
\hline \multicolumn{5}{|c|}{ Enter Plutonium Abundances } \\
\hline Pu Analysis Daze: & YY.MY.DD & Am Analy & ysis Date & : YY.MY.DO \\
\hline QPu-238 Abundance: & 99.9999 & $P u-238$ & E Error: & 99.9999 \\
\hline 8 Pu-239 Abundance: & 99.9999 & Pu-239\& & Error: & 99.9999 \\
\hline \&u-240 Abundance: & 99.9999 & Pu-240 & Eszor: & 99.9999 \\
\hline \&u-241 Abundance: & 99.9999 & Pu-241 함 & fit Errez: & 99.9999 \\
\hline \&Pu-242 Abundance: & 99.9999 & Pu-242 \& & Error: & 99.9999 \\
\hline grm-241 Abundance: & 99.9999 & $A m-241$ z & \& Error: & 99.9999 \\
\hline
\end{tabular}

$\begin{array}{cccc}\text { Type In Value } & \uparrow, \downarrow \text { and } \downarrow & \text { PgDn } & \text { Exc } \\ \text { Move Field Cursor } & \text { Exit Screen Abort Screen }\end{array}$

Figure 13. Enter Plutonium Abundances form.

The Batch Sample information form (Fig. 14) is provided only for recording sample information. It is not necessary to complete this form to perform an analysis. The form needs to be completed only once for a series of measurements on samples from the same batch. When all of the necessary or desired information has been entered, $\angle \mathrm{PgD} n>$ exits the form and returns to the Plutonium Analysis menu option list. 
IAEA Plutonidn Analysis System

88.08 .03

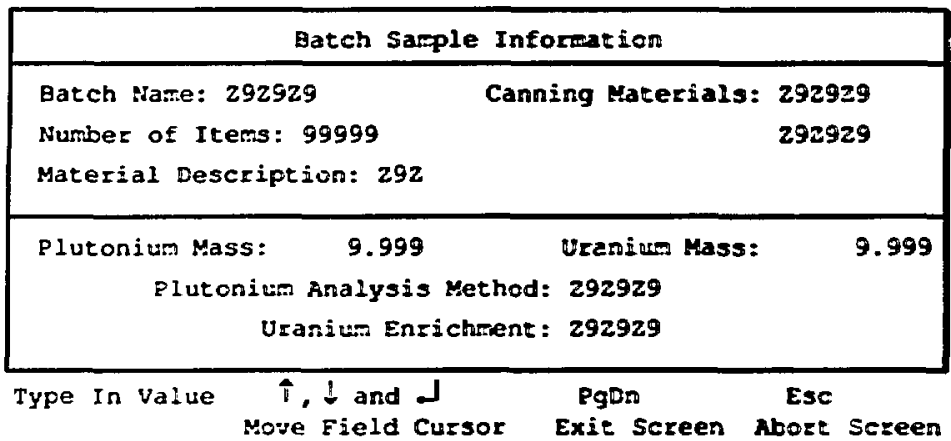

Figure 14. Batch Sample Information form.

When the user is in the Plutonium Analysis oplion menu, $<A>$ tollowed by <enters starts the analysis. If the analysis output is directed to tive screen, the output begins with a listing of information regarding the spectrum (see Fig. 15). The last four linss appear only if peak areas are requested in the report.

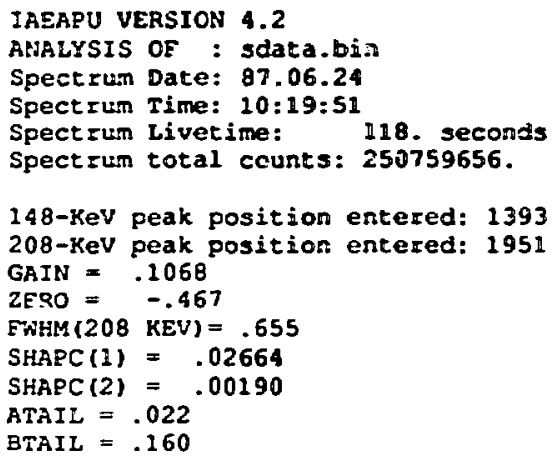

Figure 15. Analysis report header.

Next, the message

Press enter to continue...

is displayed to prevent the output from "rolling off" the top of the screen before the user has a chance to examine it. To permit the output to continue, the user must press the 'enter' key. If the peak area information is not requested, the screen will display thr message

Working on Group 
to indicate that the computer is working on the analysis. This message is also displayed if the oulput is directed to the printer or a disk file. The final part of the output gives the plutonium isolopic ratios and weight percent abundances.

the analysis:

If the output is directed to a disk file, the following messuge will appear at the beginning of

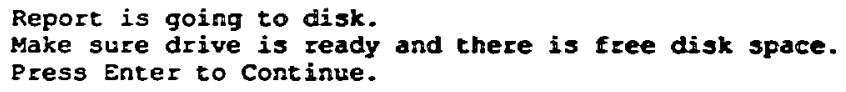

$<$ Enter> will cause

$$
\text { Horking on Group <4> }
$$

to appear on the screen.

Working on Group <\$> will not appear unless the printer is enabled. If the printer is not available, the message

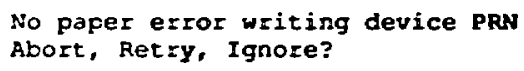

will be displayed, and the user should take appropriate action.

The last question on the form in Fig. 11:

Include Peak Areas in Report $\{\mathbf{Y}, \mathbf{N}\}$ :

enables the output of peak areas for diagnostic purposcs. An cxample of this output is shown in Fig. 16. When output is to the screen, only one "screenful" of the puak-area information is oulput to the screen at a time. When continuation of the report is desired, <enters is done to continue, as is requested at the bottom of the screen. 


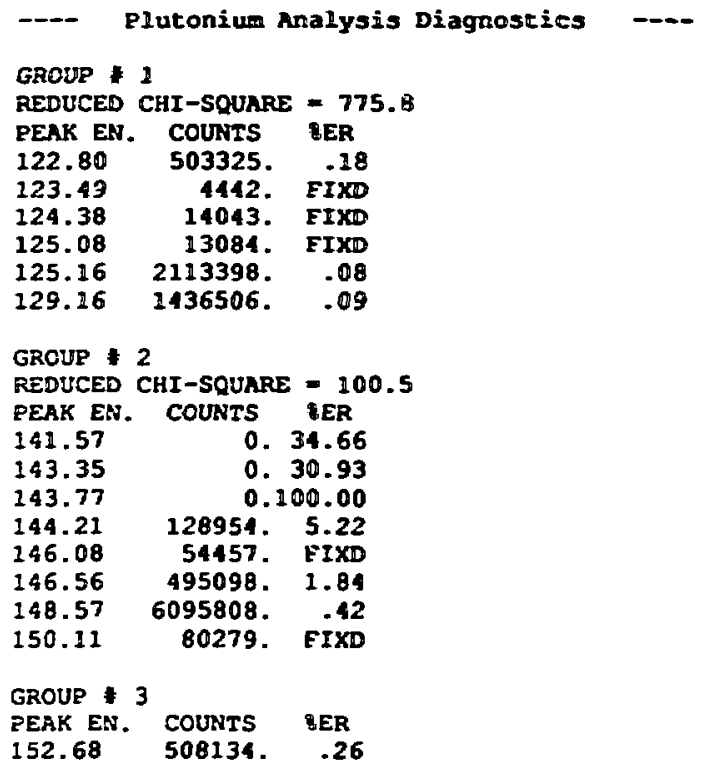

Figure 16. Analysis report diagnostic oulput. 
IAEAPU ANRLYSIS OF SPECTRUM: sdata.bin

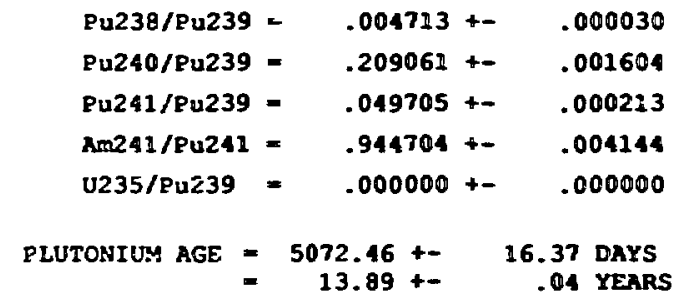

MEAS.

DECAY CORR.

HT.PCT. RBS. ERR

OPERATOR WT.PCT.

(H-O)

PU238 $=.3687+-.0022$

PU239 $=78.2332+-.1408$

PU240 $=16.3555+-.1055$

PU241 $=3.8886+-.0143$

PU242 $=1.1540+-.1154$

AM241 $=3.6736+-.0068$

.3650

1.0000

77.9210

.2000

16.6830

$-1.9608$

3.8500

1.0000

1.1540

.0000

3.5666

3.0000

$\begin{aligned} \text { U235/PU RATIO } & =.0000+-.0000 \\ \text { PU240 EFFECTIVE } & =19.0855+-.2185\end{aligned}$

SPECIFIC POWER $(\mathrm{mW} / \mathrm{g})=9.0888+-.0123$

VALUE OF $T * 2=$

27.699

Figure 17. Analysis Report-results.

The Analysis Report includes the decay corrected operator weight percent abundances and (MO)\% (measured - oper stor percent difference) columns, if the declared operator plutoni are provided. Note: t'ie declared abundances are decay-corrected only if the spectrum measurement date exists in the MC, $\triangle$ PAR.DBF file. For the measurement date to exist in this file, the spectrum must have been transferred with the Data Transfer option.

If the measurement date does not exist, then the isolopic abundances must be decay-corrected before they are entered into the Plutonium Abundance form.

When the analysis is completed, the program reterns to the top-level menu. If the analysis

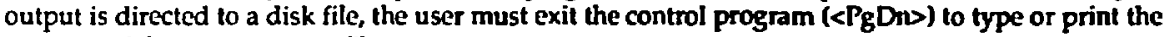
contents of the output report file.

Analysis Error Messages

\section{BAD PEAK POSITION FOR REFERENCE PEAK \\ Press Enter to continue}

If the position for the $148-$ or $208-\mathrm{keV}$ peak is incorrect, and statistically insignificant data exists at the position given, this message will be displayed. This message may also indicate that the data stored in the data file is bad and cannot be analyzed. First, the user should check positions of peaks given and, if okay, check the data in the disk file.

BAD PEAK-WIDTH PARAMETER; CHANNEL OVERELOW? 
If the prak-width parameter has the wrong sign, this message is displayed. The most likely cause is a channel overflow in the reference peak. The user should check the spectrum. The spectrum cannot be analyzed if channel overflows exist.

\section{BAD GAIN; CHECK PEAK POSITIONS}

If the product of the spectrum gain and the maximum number of channcls in the spectrum, plus the zero-channel energy is less than $210 \mathrm{keV}$, this message is displayed. The 208-keV peak must be included in the spectrum for the analysis to be completed. Adjust the ampififer gain to include the 208$\mathrm{keV}$ peak in the spectrum.

GAD 2ERO; CHECK PEAK POSITIONS

If the channel-zero energy is greater than $121.5 \mathrm{keV}$, this message is displayed. A channelzero energy greater than $121.5 \mathrm{keV}$ precludes analysis of the 120-keV peak grouping, which is requircd by the analysis program. This condition may occur because of an incorrect peak-position entry or an improper energy calibration.

\section{POOR RESOLUTION}

If the FWHM of the 208-keV peak exceeds $1.15 \mathrm{keV}$, a waming message is displayed to warn the user that the spectral resolution is not good and that the results are questionable. Although the data will be analyzed, the user should take action to improve the energy resolution. This action may involve simply reducing the count rate, or it may involve adjusting the sroplifier pole zero and sluping time constant (consult the IMI for more details).

\section{CHECK REFERENCE PEAK POSITION}

This error mussage will occur if incorrect peak positions were given for the 148-and 2nb-keV peaks. The calculated gain and zero may satisly ihe necessary conditions and will be printed out; however, the program will check to make sure that the $129.3-\mathrm{keV}$ peak is found in the correct position. The analysis program will not continue. Check and verify that the correct reference peak positions were given.

\section{BAD $375.0 \mathrm{kEV}$ PEAK}

If the 300-keV peak regions are included in the spectrum, the analysis program uses the $375.0-\mathrm{keV}$ peak as a reference to adjust the gain. If the $375.0-\mathrm{keV}$ peak is nonexistent or the data in the spectrum disk file is bad, this error will be displayed.

$$
<\text { Energy>-kev peak area is }<=0 \text {. Analysis aborted }
$$

If any of the peak areas used for establishing the relative detection efficiency for the measurement are 0 , this error message is displayed. These peaks must exist for the analysis to be completed. If the displayed spectrum shows significant peaks, the user should check the spectrum disk file for bad data.

$$
\begin{aligned}
& \text { Significant pileup effects found in spectrum. } \\
& \text { Results may be suspect. Check count rate and pole zero. }
\end{aligned}
$$

The high-energy side of the $20 \mathrm{~s}-\mathrm{keV}$ peak is checked for pileup effects. If the pileup effects are significant, this message is displayed. The reason for the pileup should be found and eliminated, because it may bias the results. 
Large scattering peaks observed in spectrum.

Analysis will be performed, but results may be suspect

Check measurement setup. Remove objects causing scattering.

Gamma-rays scaltering off of objects surrounding the detector may cause broad sloping distributions in the spectrum that make determination of background and peak areas less accurate. The user should locate sources of scattering and modify the counting setup or remove objects.

\section{Output of Data-Base Records}

If the user perlorms analysis on the same spectrum more than once, the application will keep only the most recent values in the data base. This is to say that multiple records for the same spectrum and sample number will NOT be kept. If multiple analyses need to be kept, then changing the spectrum name or sample number will be required.

\section{Quality-Assurance Analysis}

This program is selected from the top-level menu by $<\mathrm{C}>$ and $<e n t e r\rangle$. The purpose of the quality-assurance program is to check certain parameters delermined from a gamma-ray spectrum for system setup and performance. The paramelers are determined by analyzing low-and high-energy gamma-ray peaks in the spectrum. The program may be applied to a gamma-ray spectrum of any gamma-ray emitter (i.e., it does not have to be a plutonium gamma-ray spectrum).

Inputs to the program are the energies and channel positions of the low-and high-energy gamma-ray peaks and the spectrum filename. The two peaks should be well isolated (free from interferences) and should contain a minimum of $10^{5}$ counls (or $2 \times 10^{4}$ peak height) to ensure a good determination of the gamma-ray peak shape. Outputs from the program are the gain and channel-zero energy of the spectrum, as well as the calculated spectral resolution at 122 and $208 \mathrm{ke} \%$.

The gain and zero are checked to determine if they are appropriate for plutonium gamma-ray isotopic analysis. If the gain of the system is greater than $0.15 \mathrm{keV} /$ channel, the message

\section{Gain MUST BE LESS than $0.15 \mathrm{keV} / \mathrm{channel}$}

is displayed on the screen. Plutonium isotopic results may be compromised if the gain is higher than $0.15 \mathrm{keV} /$ channel. This is because of requirements by the analysis program that the channel spacing between peaks not be below a minimum value. It is recommended that the gain be approximately $0.11 \mathrm{keV} /$ channel. The zero-channel energy (zero) is checked and the message

\section{CHECK ZERO; ZETO CANNOT BE GREATER than $121.5 \mathrm{keV}$}

is displayed if the zero-channel energy is greater than $121.5 \mathrm{keV}$. A zero-channel energy greater than $121.5 \mathrm{keV}$ precludes analysis of the $120-\mathrm{keV}$ peak grouping, which is required by the isotopic analysis program. The energy range of the spectrum is also checked. If the product of the spectrum gain and maximum channel in the spectrum plus the zero-channel energy is less than $210 \mathrm{keV}$, then the message

CHECK GAIN; Upper energy range MUST BE AT LEAST $210 \mathrm{keV}$

is displayed. The isotopic analysis program cannot analyze a plutonium gamma-ray spectrum, if the 208-keV peak region is not included. The above requirements on the gain and zero must be met by plutonium gamma-ray spectra that are to be analyzed for plutonium isotopics.

If the quality assurance program is used to check the quality of spectra other than plutonium spectra, these conditions may be ignored. The isotopic analysis program also performs the checks described above. 
The program also checks the resolution performance of the system at $208 \mathrm{keV}$. If the resolution is greater than $1.15 \mathrm{keV}$, then the message

$$
\text { PCOR RESOLUTION -- CHECK SYSTEM AND COUNT RATE }
$$

is displayed. It is recommended that resolution at $208 \mathrm{keV}$ for a plutonium gamma-ray spectrum be no greater than $800 \mathrm{eV}$ for the best results. The high-energy peak is also inspected for high-energy tailing caused by pulse pileup. The following message is displayed if high-energy tailing is significant:

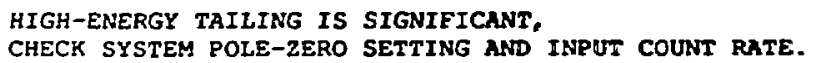

High-energy tailing may be a symptom of improper pole-zero adjustment or high input count rate. The measurement siluation should be checked for both of these conditions. High-encrgy tailing may also be an indication of poor detector performance (slow risctime pulses). In such cases the detector should be replaced or refurbished.

When the quality assurance program is completed, it retums to the main option menu.

IAEA Plutonium Analysis System 88.08 .03

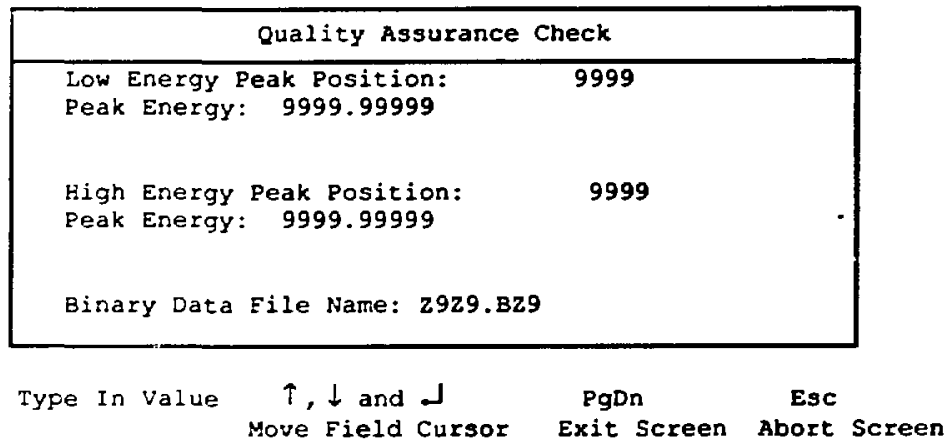

Figure 18. Quality Assurance Check form)

\section{Ending the Program}

Exiting the main option menu is done by $<e s c>$ or $\langle Q\rangle$ when the main option menu is displayed. The main control program displays the message

$$
\text { Ending IAEA Plutonium Acquisition and Analysis Program }
$$

and relums the system to the MS-DOS prompl. To restart the main control program and display the main option menu, the user types 'IA' after the MS-DOS prompt, as shown in the beginning of the operating instructions. 


\section{Installation}

\section{Distribution Media}

There are five diskettes supplied: four 3.5-in. diskettes and one 5.25-in. diskette.

1. Master Program Diskette :

2. Master Data Diskette :

3. Maintenance Diskette : FORTRAN sources :

FORTRAN include files :

FORTRAN libraries :

dBASE sources :

dBASE libraries :

MAKE files :

Installation files :

FLASHCODE window libraries :

\begin{tabular}{|c|c|c|}
\hline $\begin{array}{l}\text { ia.bat } \\
\text { iaca.exe } \\
\text { panal.win } \\
\text { cictrans.win }\end{array}$ & $\begin{array}{r}\text { master.exe } \\
\text { defaults.dbf } \\
\text { defchang.win } \\
\text { tempinfo.dbf }\end{array}$ & $\begin{array}{r}\text { unflash.exe } \\
\text { Anunexe } \\
\text { mainwind.win } \\
\text { filename.cic }\end{array}$ \\
\hline bf & $\begin{array}{r}\text { anresult } \\
\text { iaca }\end{array}$ & $\underset{\text { filen }}{\mathrm{dcl}}$ \\
\hline
\end{tabular}

\begin{tabular}{|c|c|c|c|}
\hline $\begin{array}{l}\text { ave.for } \\
\text { diaea.for } \\
\text { bkgd.for } \\
\text { nents.for } \\
\text { ctail.for } \\
\text { diags.for } \\
\text { idpmy.for }\end{array}$ & $\begin{array}{r}\text { c2jdat.for } \\
\text { dsave.for } \\
\text { maxval.for } \\
\text { rdsk.for } \\
\text { gfit2.for } \\
\text { more.for } \\
\text { tlest.for }\end{array}$ & $\begin{array}{r}\text { decay.for } \\
\text { bwf.for } \\
\text { slripl.for } \\
\text { bkgrd.for } \\
\text { pufity.for } \\
\text { matinu.for } \\
\text { dchdal.for }\end{array}$ & $\begin{array}{r}\text { ia.for } \\
\text { dcheck.for } \\
\text { master.for } \\
\text { cicero.for } \\
\text { getd.for } \\
\text { anresult.for } \\
\text { sppow.for }\end{array}$ \\
\hline
\end{tabular}

iaea.cmn iacadb.cmn top.cmn

commsub.lib iacafor.lib filesub.lib

grafsub.lib acssub.lib dbsubs.lib

iaea.prg
cicdala.prg
dch.prg
decfnum.prg
getstrg.prg
getnum.prg

prgs.lib compchem.lib

prg.mak for.rnak

installh.bal

panal.win

cictrans.win mainwind.win defchang.win

$$
\begin{array}{rr}
\text { funkey.prg } & \text { getkey.prg } \\
\text { getiadal.prg } & \text { getcool.prg } \\
\text { enditall.prg } & \text { chdefalt.prg } \\
\text { inputban.prg } & \text { getwhnum.prg } \\
\text { getdate.prg } & \text { gettime.prg }
\end{array}
$$

4. Documentation Diskette :

ASCII text files :

Volkswriter 3 format files :

5. Data Structures Diskette: (5.25") readme.txt data.fmt

jaearef.doc

iadefalt.dbf mcapar.dbf opinstr.txt

login.cc

anresult.dbf iaea.dbf dcheck.dbf

filename.dbf 


\section{Systems with Two 720-KB Disks}

\section{(Installations on systems without hard disks cannot support maintenance of the program.)}

(Installation wiil NOT be successful on systems with 360KB floppy disk drives and NO hard dist.)

Generating a Program Diskette can be done by simply copying the disk labeled "Master Program Disk." Generating a Data Diskette can be done by simply copying the disk labeled "Masler Data Disk." Installation is done by simply placing the program disk in drive $A$ and the data disk in drive $B$. In order to use the IAEA syslem on a floppy-based system, the only disks nezded are the PROGRAM and DATA disks. The PROGRAM disk must go in drive $A$ and the DATA disk in B. The Change Defaults option from the main menu is used to change the drive to B. If the user has a path on the disk for data files and wants to use that as the default, the path should be entered at the path prompt.

\section{Systems with Hard Disks}

To use this system on a computer with a hard disk, the user must copy all the files on the "Master Program Disk" to a subdirectory on the hard drive. We suggest the "c:liaea" subdircetory, but the spectral data files may be placed anywhere, as long as the user either enters the drive and path for the data files in the filename prompt or enters the drive and path in the Set Defaults option. Additional files need to be loaded on the hard disk if maintenance is to be performed on the program.

Use of the INSTALLH.BAT will set up the hard disk so that maintenance can be performed.

\section{Maintenance}

The IAEA Plutonium Isotopics Analysis Program is comprised of a Microsoft(c) FORTRAN application, a Clipper(c)-compiled dEASE III(c) front-end program, and some MS-DOS(c) "BAT" command files.

If maintenance needs to be performed, it is necessary that this activity take place on a system with a hard disk.

System software required for use:

- Microsoft or IBM MS-DCS or PC-DOS, Revs. 2.1 to 3.3

- Ashton-Tate dBASE III (optional, for viewing data-base files)

- Software Bottling of N.Y. FLASHCODE run-time files.

System software required for maintenance:

- Microsoft or IBM MS-DOS or PC-DOS, Revs. 2.1 to 3.3

- Ashton-Tate dBASE III (optional, for viewing data-base files)

- Microsoft FORTRAN-77, Rev. 4.01 (other revision levels might necessitate recompilation and source-code modification)

- Microsoft LINK, Rev. 3.55

- Microsoft LIB, Rev. 3.06

- Microsoft MAKE, Rev. 4.05

- Nantucket CLIPPER cornpiler, Summer 87 Revision or later

- A text editor appropriate for source-code modification.

- Software Bottling of N.Y. FLASHCODE

Hardware required for maintenance:

- IBM-PC/XT/AT compatible system with hard disk if the system does not have a 35-in., 720KB floppy disk drive, the user will need cabling and software to transfer software to the Toshiba $1100 / 2100$ for use. The system software mentioned previousl'r needs to be installed on the systern on which maintenance will be performed. The source code is supplied and is loaded onto the system by 
using the INSTALLH.BAT command procedure. In onder so recompile the code, we use a Make file to automale the process. First, the appropriate compiler needs to be installed on the hand disk The user will not be able to recompile the application from a floppy-based system. IAEA.EXE is the user interface, and MASTER.EXE performs the data transfex, analysis, and quality assurance. The sources with PRG extensions are compiled with Clipper and create IAEAEXE. The sources with FOR extensions are the FORTRAN sources and are compiled with the FORTRAN compiler.

\section{To Rebuild IAEA.EXE}

Type MAKE PRG.MAK <Enter>. This will run the program MAKE.EXE. Make will read the file PRG.MAK and compile the sources that have been changed since the last compile. (See the section in the FORTRAN manual about Make and make filcs for a detaiked description of Make.)

Make will call the compiler spexified in the top of the Make file PRG.MAK. The compiler must be installed properly and be available along the DOS Path. The source files must be in the current disk directory. This process is completely automated, and if the compiler is instalket properly and there are no errors in the new code, the new IAEA.EXE will be gencrated. It is now ready to use.

\section{To Rebuild MASTER.EXE}

Type MAKE FOR.MAK <cr>. This process is the same as rebuilding IAEA.EXE. The FORTRAN coritpiler must be available along the DOS palh, and the source files must be in the current directory. for use.

If the compilation and linking goes properly, a new MASTER.EXE is now created and is ready

For the FORTRAN program, certain libraries must be available for linking. These can be in the current directory or available along the path specificd by the Lle environment variable.

These libraries are as follows:

COMMSUB.LIB

GRAFSUB.LIB

ACSSUB.LIB

FILESUB.LIB

DBSUBS.LIB

IAEAFOR.LIB

A user who has systems with and without $80 \times 87$ math coprocessors will need to use the "rmulator" library LLIBFORE and the appropriate command switches when compiling. Otherwise, the "alternative" library LLIBFORA should be used along with the appropriale command switches for the compiler.

\section{Spectral Data-File Formats}

The analysis application understands two formats: binary and ASCII. The ASCII format is casily read or edited by a person, but it requires twice the space on disk and takes more than twice as long for a computer to read or write as binary. It is expected that most catalogued speclra will be stored in the binary format.

In ASCII, all values are written/read in FORTRAN F8.0 format. In binary, all values are written/read as I*4 variables by using FORTRAN binary WRITES or READS. In either format, values are as follows:

$\begin{array}{lll}1 \text { value } & - & \text { spectra id } \\ 1 \text { value } & - & \text { livetime } \\ n \text { values } & - & n \text { channels of count values }\end{array}$




\section{dBASE III Data Structures}

The following are descriptions of the dBASE 111 dala structures for the files used by the WAEA plutonium applicalion suitc:

FIELD The number of the ficld within the file FIELD

NAME The name of the indicalcd field, used for referencing that field

TYP

The type of the ficld : $C$ is character

Nis numeric

$D$ is dale

WIDTH The width of the field, in byles (characters or digits)

DEC The number of decimals in a numeric field.

(A WIDTH of 8 and a DEC of 4 indicate numbers formalted and slored as $\$ 99.9999$. ) 
File cescriptica :

File Name

Record Lengts

Current Date : malysis defaules

TREEERLE.DAF

$3 \div 5$

5 : 1997

\begin{tabular}{|c|c|c|c|c|c|}
\hline FIELD & NAME & TE & Graza & EEc & \multirow{8}{*}{ 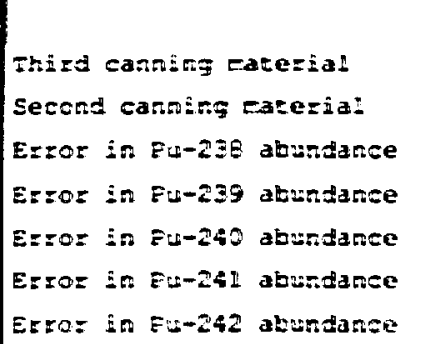 } \\
\hline 1 & CNAT3 & $c$ & 15 & 0 & \\
\hline 2 & CMA:2 & $c$ & Is & 0 & \\
\hline 3 & PU23EERR & si & $\mathrm{e}$ & 4 & \\
\hline 4 & PU239ERE: & $\because$ & $\mathrm{e}$ & 4 & \\
\hline 5 & PU240EFE & $\because:$ & $\mathrm{a}$ & 9 & \\
\hline 6 & PU24 IERE & $\because:$ & e & 4 & \\
\hline 7 & PU242ERE & : & 8 & 9 & \\
\hline 8 & $A \backsim 241 \equiv R R$ & $\because:$ & $E$ & 4 & \multirow{2}{*}{ 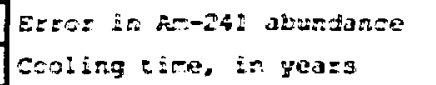 } \\
\hline 9 & CCOLI:S & $::$ & 5 & 0 & \\
\hline 10 & A:4241 & $\because:$ & 22 & $;$ & \multirow{9}{*}{ 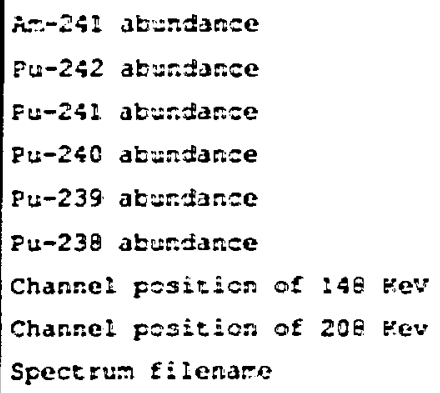 } \\
\hline 11 & PU242 & $\therefore:$ & 10 & $;$ & \\
\hline 12 & PU2द1 & $\because$ & 10 & 4 & \\
\hline 13 & PU260 & $\because \mathbf{i}$ & 10 & 4 & \\
\hline 14 & PU239 & u & 12 & 4 & \\
\hline 15 & ?u238 & i & 20 & 4 & \\
\hline 16 & POS148 & $\mathrm{C}$ & 20 & 0 & \\
\hline 17 & POS 208 & $c$ & 20 & 0 & \\
\hline 18 & SPECFIMAME & C & 30 & 0 & \\
\hline 19 & REPF:PME & $c$ & 30 & 0 & \multirow{2}{*}{$\begin{array}{l}\text { Report SIlename } \\
\text { Output rode }\end{array}$} \\
\hline 20 & CUTPJ: & $c$ & 1 & 0 & \\
\hline 21 & BATCH & $c$ & 15 & 0 & \multirow{10}{*}{$\begin{array}{l}\text { Batch identification } \\
\text { Number of itens } \\
\text { Total plutonium mass } \\
\text { Plutcmitm analysis date } \\
\text { Arericium analysis date } \\
\text { method of Pu analysis } \\
\text { Total uranium mass } \\
\text { Uranium enrichment } \\
\text { Material description ccde } \\
\text { Eirst canning material }\end{array}$} \\
\hline 22 & NOITEM & $c$ & 5 & 0 & \\
\hline 23 & TPUMAS & $\therefore$ & 12 & 3 & \\
\hline 24 & PUDATE & D & B & 0 & \\
\hline 25 & AMDATE & D & 8 & 0 & \\
\hline 26 & METHOD & $c$ & 20 & 0 & \\
\hline 27 & TUMAS & $\mathrm{N}$ & 12 & 3 & \\
\hline 28 & ENRICS & C & 10 & 0 & \\
\hline 29 & $M D C$ & C & 15 & 0 & \\
\hline 30 & CMAT & $c$ & 15 & 0 & \\
\hline
\end{tabular}


File Description : File Name Record Length

Current Date
Temporary Stozage

EILERHKE. DEF

31

5 MOV 1997

\section{\begin{tabular}{|l|l|l|l|l}
\hline EIELD & NAME & TYP & HIDTH & DEC
\end{tabular}}

\begin{tabular}{l|l|l|l}
1 & FI LSHAIE & $C$ & 30
\end{tabular}

File Description :

Eile Narre

Record Length :

Current Date :

Temporary Stozage

IUP. DEF

181

5 MOV 1987

\begin{tabular}{|c|c|c|r|r|}
\hline EIELD & NAME & TYP & HIDTH & DEC \\
\hline 1 & STUEE & $C$ & 180 & $\emptyset$ \\
\hline
\end{tabular}

File Description :

Iransfer Parameters

File Name

YCAPRR . DEE

Record Length :

362

Current Date :

$5 \mathrm{ROV} 19 \mathrm{~g}$

\begin{tabular}{|c|c|c|c|c|c|}
\hline EIELD & MALAE & TYP & NIDTH & DEC & \multirow{6}{*}{$\begin{array}{l}\text { sample number } \\
\text { channel position of } 208 \mathrm{keV} \\
\text { channel position of } 143 \mathrm{keV} \\
\text { spectrum filename }\end{array}$} \\
\hline 1 & SAMPLENUM & C & 10 & 0 & \\
\hline 2 & POS208 & $\mathbf{N}$ & 8 & 3 & \\
\hline 3 & POS148 & $\mathrm{H}$ & 8 & 3 & \\
\hline 4 & ENAME & $c$ & 30 & 0 & \\
\hline 5 & PUR & c & 4 & 0 & \\
\hline 6 & RATE & c & 4 & $\mathbf{0}$ & \multirow{2}{*}{$\begin{array}{l}\text { pile-up sate sete } 1 \text { ng } \\
\text { pole-zero adjustrent }\end{array}$} \\
\hline 7 & PZA & C & 20 & $\mathbf{0}$ & \\
\hline 8 & INPOL & $c$ & 6 & 0 & \multirow{3}{*}{$\begin{array}{l}\text { Input switch polarity } \\
\text { baseline restore(BLR) adjustant } \\
\text { BLR shape setting }\end{array}$} \\
\hline 9 & BLRL & C & 4 & $\mathbf{0}$ & \\
\hline 10 & BLRS & C & 4 & $\mathbf{0}$ & \\
\hline 11 & DTS & c & 4 & $\mathbf{0}$ & \multirow{3}{*}{$\begin{array}{l}\text { dead time setting } \\
\text { input tode setting } \\
\text { base line coment }\end{array}$} \\
\hline 12 & INPMD & c & 5 & $\mathbf{0}$ & \\
\hline 13 & BASE & C & 20 & 0 & \\
\hline
\end{tabular}




\begin{tabular}{|c|c|c|c|c|c|}
\hline FIELD & NAME & TYP & SIDTH & DEC & \multirow{9}{*}{$\begin{array}{l}\text { rise tire protection } \\
\text { high-voltage polarity } \\
\text { shaping tire } \\
\text { coarse gain } \\
\text { fine gain } \\
\text { rise time protection (usec) } \\
\text { detector bias high-voltage }\end{array}$} \\
\hline 14 & RTPS & c & 4 & 0 & \\
\hline 15 & HUPOL & C & 3 & $\mathbf{0}$ & \\
\hline 16 & SHAPET & N & 12 & 2 & \\
\hline 17 & CGAIN & $\mathbf{N}$ & 12 & 2 & \\
\hline 18 & FGAIN & $N$ & 12 & 2 & \\
\hline 19 & RTPT & $N$ & 12 & 2 & \\
\hline 20 & HVOLT & $\mathbf{N}$ & 12 & 2 & \\
\hline 21 & DISCR & $\mathbf{N}$ & 12 & 2 & \\
\hline 22 & CNTRY & c & 8 & $\mathbf{0}$ & country \\
\hline 23 & ECLTY & C & 6 & 0 & facility \\
\hline 24 & MBA & C & 6 & $\mathbf{0}$ & material balance area code \\
\hline 25 & KM & c & 6 & $\mathbf{0}$ & key measurement point code \\
\hline 26 & REPORT & C & 12 & $\mathbf{0}$ & inspection report nurber \\
\hline 27 & DATE & D & B & $\mathbf{0}$ & date of inspection \\
\hline 28 & INSPTR & C & 24 & 0 & inspector identification \\
\hline 29 & RMRKS & C & 69 & 0 & remarks \\
\hline 30 & MEASDATE & D & 8 & $\mathbf{0}$ & date of measurement \\
\hline 31 & MEAST IME & C & 8 & 0 & time of measurement \\
\hline
\end{tabular}




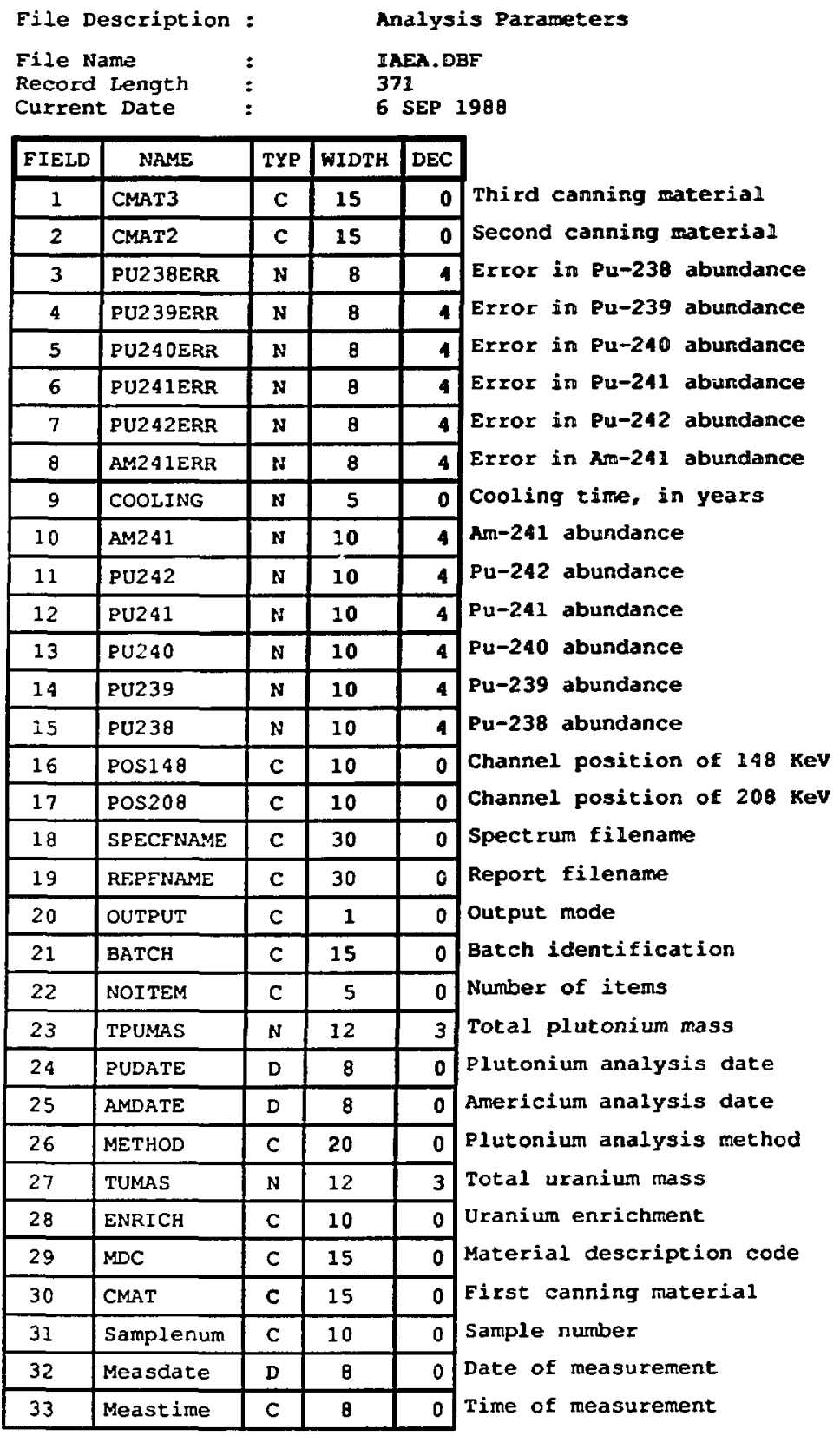


File Description :

File Name

Record Length

Current Date :
Analysis Results

ANRESULT.DBF

641

5 Nov 1987

\begin{tabular}{|c|c|c|c|c|c|}
\hline FIELD & NAME & TYP & FIDTH & DEC & \multirow{8}{*}{$\begin{array}{l}\text { Spectrun Filename } \\
\text { Sample Number } \\
\text { Pu-238 abundance } \\
\text { Pu-239 abundance } \\
\text { Pu-240 abundance } \\
\text { Pu-241 abundance } \\
\text { Pu-242 abundance }\end{array}$} \\
\hline 1 & SPECFNAME & c & 30 & 0 & \\
\hline 2 & SAMPLE & C & 10 & 0 & \\
\hline 3 & PU238 & H & 8 & 4 & \\
\hline 4 & PU239 & $\mathrm{N}$ & 8 & 4 & \\
\hline 5 & PU240 & $\mathbf{N}$ & 8 & 4 & \\
\hline 6 & PU241 & $\mathbf{N}$ & 8 & 4 & \\
\hline 7 & PU242 & $N$ & 8 & 4 & \\
\hline 8 & $P E 238$ & $y$ & 8 & 4 & \multirow{6}{*}{$\begin{array}{l}\text { Error in Pu-238 abundance } \\
\text { Error in Pu-239 abundance } \\
\text { Error in Pu-240 abundance } \\
\text { Error in Pu-241 abundance } \\
\text { Error in Pu-242 abundance } \\
\text { Specific power }\end{array}$} \\
\hline 9 & $P E 239$ & $n$ & 8 & 4 & \\
\hline 10 & $\mathrm{PE} 240$ & $N$ & 8 & 4 & \\
\hline 11 & PE241 & $\mathbf{N}$ & 8 & 4 & \\
\hline 12 & PE242 & N & 8 & 4 & \\
\hline 13 & POW & $\mathbf{N}$ & 8 & $\dot{4}$ & \\
\hline 14 & PONE & $\mathrm{N}$ & 8 & 4 & \multirow{6}{*}{$\begin{array}{l}\text { Error in specific power } \\
\text { Effective Pu- } 240 \\
\text { Error in effective Pu-240 } \\
\text { INVERTED MATRIX ELEMENTS }\end{array}$} \\
\hline 15 & $E 240$ & $\mathbf{N}$ & 8 & 4 & \\
\hline 16 & E2 $40 E$ & $\mathbf{N}$ & 8 & 4 & \\
\hline 17 & ALPHA1 1 & $\mathbf{N}$ & 15 & 8 & \\
\hline 18 & APLHA 12 & $\mathbf{N}$ & 15 & 8 & \\
\hline 19 & ALPFA13 & $N$ & 15 & 8 & \\
\hline
\end{tabular}




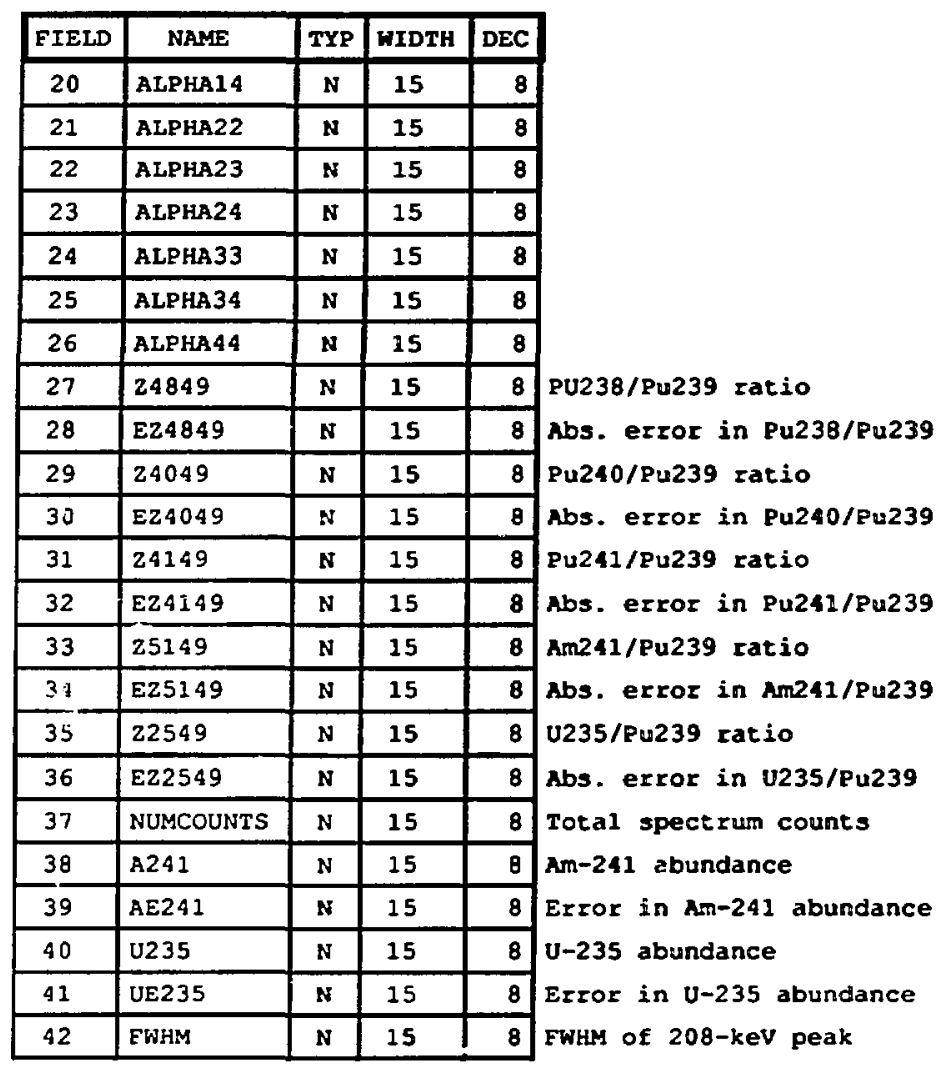




$\begin{array}{lll}\text { File Description } & & \text { Quality Assurance } \\ \text { File Name } & : & \text { DCHECK.DBE } \\ \text { Record Length } & : & 236 \\ \text { Current Date } & : & 5 \text { NoV } 1987\end{array}$

\begin{tabular}{|c|c|c|c|c|c|}
\hline FIELD & NAME & TYP & WIDTH & DEC & \multirow{7}{*}{$\begin{array}{l}\text { Spectrum filename } \\
\text { Position of reference peak } 1 \\
\text { Energy of reference peak } 1 \\
\text { Position of reference peak } 2 \\
\text { Energy of reference peak } 2 \\
\text { livetime }\end{array}$} \\
\hline 1 & FNAME & c & 30 & 0 & \\
\hline 2 & NREF 1 & $\mathbf{N}$ & 11 & 0 & \\
\hline 3 & STD1 & $\mathbf{N}$ & 11 & 5 & \\
\hline 4 & NREF 2 & $\mathbf{N}$ & 11 & 0 & \\
\hline 5 & STD2 & $\mathbf{N}$ & 11 & 5 & \\
\hline 6 & LIVTIM & $\mathbf{N}$ & 11 & 0 & \\
\hline 7 & CRATE & $\mathbf{N}$ & 11 & 5 & \multirow{4}{*}{$\begin{array}{l}\text { Count rate } \\
\text { Channel zero energy } \\
\text { Spectrum gain (kev/channel) } \\
\text { Eull-width-half-max peak } 1\end{array}$} \\
\hline 8 & ZERO & $\mathbf{N}$ & 11 & 5 & \\
\hline 9 & GAIS: & $\mathbf{N}$ & 11 & 5 & \\
\hline 10 & พЕพHM1 & $\mathbf{N}$ & 11 & 5 & \\
\hline 11 & SEWHM1 & $\mathbf{N}$ & 11 & 5 & \multirow{10}{*}{$\begin{array}{l}\text { Standard deviation of FWHMI } \\
\text { Peak shape parameter } \\
\text { Peak shape parameter } \\
\text { Area of peak } 1 \\
\text { Standard deviation of AREA1 } \\
\text { FWHM of peak } 2 \\
\text { Standard deviation of FWHM2 } \\
\text { Area of peak } 2 \\
\text { Standard deviation of AREA2 } \\
\text { Pile-up flag }\end{array}$} \\
\hline 12 & SHAPC2 & $N$ & 11 & 5 & \\
\hline 13 & SHAPC1 & $\mathbf{N}$ & 11 & 5 & \\
\hline 14 & PAREAI & $N$ & 13 & 5 & \\
\hline 15 & SPAREA 1 & $\mathbf{N}$ & 11 & 5 & \\
\hline 16 & ผЕWHM2 & $\mathbf{N}$ & 11 & 5 & \\
\hline 17 & SFWHM2 & $\mathbf{N}$ & 11 & 5 & \\
\hline 18 & PAREA2 & $\mathbf{N}$ & 13 & 5 & \\
\hline 19 & SPAREA2 & $\mathbf{N}$ & 11 & 5 & \\
\hline 20 & PUFLG & $c$ & 3 & 0 & \\
\hline
\end{tabular}

\section{Disk File Index}

\section{Batch Files}

$\begin{array}{lll}\text { IA } & \text { BAT } & \text { Invokes entire system. Use this to run it all. } \\ \text { ME } & \text { BAT } & \text { Calls 'make' for FORTRAN sources } \\ \text { MP } & \text { BAT } & \text { Calls 'make' for dBASE sources } \\ \text { MOVELIB } & \text { BAT } & m \text { os libraries to supplied directory or drive } \\ \text { LPRG } & \text { BAT } & \text { pints dBASE sources to laserjet } \\ \text { LFOR } & \text { BAT } & \text { pints FORTRAN sources to laserjet } \\ \text { PRODUCT } & \text { BAT } \text { copies files to distribution disks } \\ \text { MOVEFOR } & \text { BAT } \text { copies FORTRAN sources to specified drive or sub-dir } \\ \text { MOVEPRG } & \text { BAT copies dBASE sources to specified drive or sub-dir } \\ \text { INSTALLH } & \text { BAT installs files off distribution disk to hard disk } \\ \text { UPDATE } & \text { BAT updates IAEA.ARC with sources and support files }\end{array}$

Information Files

FILENAME CIC written by CICERO.EOR, read by GETIADAT.PRG. spectra file name 


\section{Common Files}

IAEA

CMN

IAEADB CMIN

TOP

CMN

Data-Base Files

DCHECK DBF

DEFAULTS DBF

IAEA DBF

IADEFALT DBF

ANRESULT DBF

FIIENAME DBF

TEMPINFO DBF

MCAPAR DBE

\section{Executables}

$\begin{array}{ll}\text { MASTER } & \text { EXE } \\ \text { IAEA } & \text { EXE } \\ \text { FLRUN } & \text { EXE } \\ \text { UNELASH } & \text { EXE }\end{array}$

FORTRAN executable

dBASE executable

Flashcode executable

Flashcode executable

\section{FORTRAN Sources}

NCNTS FOR determines net counts in a specified region

DIAEA FOR writes results of analysis to TMP.PRH for dBASE saving

BKGD FOR calculate background continuum beneath peak

PUEITY FOR calculate relative detect:on efficiency curve for specified peaks

SPPOW FOR calculates specific power

DCHDAT FOR reads DCHECK.PRM for DCHECK FORTRAN routine

CTAIL FOR determines tail parameters for a gamma-ray peak

GEIT2 FOR determines peak position, height, and width from given peak data

STRLEN FOR finds string-length function

DECAY FOR calculates decay correction

CICERO FOR data-acquisition routine from CICERO to spectra data file

IA FOR

ANRESULT FOR

MASTER FOR

MAXVAL FOR

MATINV FOR

RDSK FOR

master plutonium-analysis routine

writes analysis results to IAEA.DBE

controlling FORTRAN program, calls CICERO, IA or DCHECK

determines channel with maximum count in a given region

DSAVE

performs matrix inversion on a symmetric matrix

AVE FOR saves DCHECK results to DCHECK.DBE

DIAGS EOR

BKGRD FOR

TTEST FOR

IDPMY EOR

STRIP1 FOR

DCHECK EOR

GETD EOR

RDBIN FOR

C2JDAT FOR

MORE EOR

reads ASCII spectra data file

prints analysis diagnostics (routine HRTEMP)

calculates background continuum beneath peak, allows sloping background

TESTBIN FOR

AVE $\quad$ FOR

performs $t \star \star 2$ statistical test

calculates relative detection efficiency for a given energy

subtracts out a peak from spectral data in a specified region quality-assurance routine, called by MASTER.FOR

reads OUT_IA.PRM, gets info from GETIADAT

reads binary spectra-data file

converts date to Julian date

displays 'more' message for print to screens in analysis

tests data file if it is binary or ASCII

calculates average counts in specified region 


\section{Libraries}

$\begin{array}{lll}\text { FILESUB } & \text { LIB } & \text { needed support library (part of FORLIB PLUS) } \\ \text { PRGS } & \text { LIB } & \text { dBASE routines } \\ \text { COMPCHEM } & \text { LIB } & \text { dBASE routines } \\ \text { GRAESUB } & \text { LIB } & \text { needed support library (part of FORIIB PLUS) } \\ \text { IAEAFOR } & \text { LIB } & \text { FORTRAN routines } \\ \text { ACSSUB } & \text { LIB } & \text { needed support library (part of FORIIB PLUS) } \\ \text { COMMSUB } & \text { LIB } & \text { needed support library (part of FORIIB PLUS) } \\ \text { DBSUBS } & \text { LIB } & \text { dBASE-FORTRAN routines }\end{array}$

Text Files

EOR

PRG

LST

IST

\section{Make Files}

PRG

FOR

MAK

MAK

dBASE Sources

$\begin{array}{ll}\text { CHECKIA } & \text { PRG } \\ \text { CICDATA } & \text { PRG } \\ \text { DCH } & \text { PRG } \\ \text { ENDITALL } & \text { PRG } \\ \text { GETIADAT } & \text { PRG } \\ \text { GETCOOL } & \text { PRG } \\ \text { CHDEFALT } & \text { PRG } \\ \text { DECENUM } & \text { PRG } \\ \text { INPUTBAN } & \text { PRG } \\ \text { IAEA } & \text { PRG } \\ \text { FUNKEY } & \text { PRG } \\ \text { GETKEY } & \text { PRG } \\ \text { GETDATE } & \text { PRG } \\ \text { GETNUM } & \text { PRG } \\ \text { GETTIME } & \text { PRG } \\ \text { GETSTRG } & \text { PRG }\end{array}$

Text file with info on making FoRTRas application

Text file with info on making dBAsE application

make file for dBASE code

make file for FORTRAN code

checks last entry of IAEA.DBF for duplicates earlier in file

CICERo front end. Full screen entry routine

DCHECK front end

displays ending banner when exiting system

analysis front end

gets cooling time for analysis

changes defaults for dBsSE system

decrements field number for CICDATA.PRG

displays bottom banner for analysis front end

top-level dBASE source file

gets a function key input

gets certain keys

gets a valid date

gets fioating-point numbers

gets a valid time

gets a string

\section{Information Files}

OUT_IA PRM written by GETIADAT, read bY GETD.FOR. Info for analysis

TMP $\quad$ PRM written by DIAEA, holds results of analysis

CICERO PRM holds data-file name fCr use by CICERO.FOR

DCHECK PRM holds DCHECK results

STATUS IA holds information for flags used in GETIADAT.PRG

Help Window Files
PANAL WIN
DEF CHANG WIN
MAINWIND WIN
CICTRANS WIN

\section{Special Notes}

Because of FORLIB PLUS, there must be a library named FORTRAN.LIB. The LLIBFORE.LIB file should be copied to FORTRAN.L.IB in the library subdirectory for the FORTRAN compiler. 
IAEA dBASE routine calling hierarchy

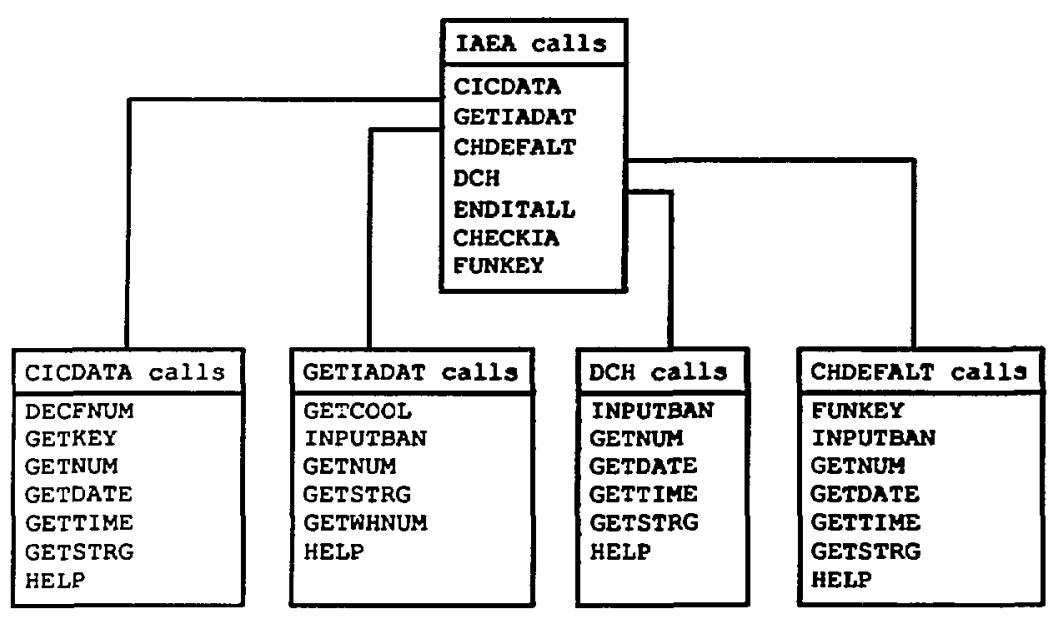




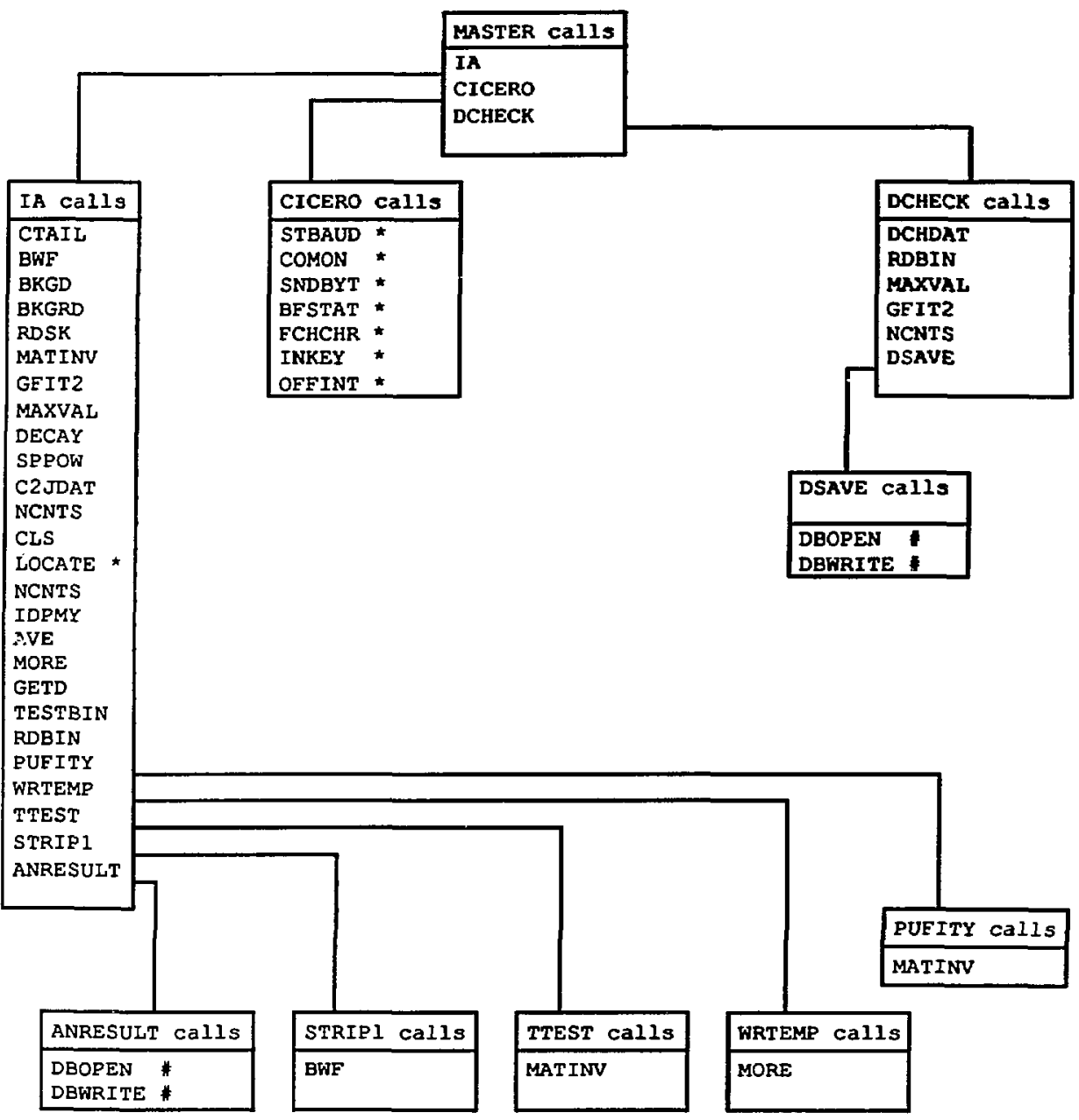

* Part of the FORLIB PLUS library package.

* Part of the fortran-dBASE library in DBSUBS.LIB.

All source files not marked '*' or '*' are in IAEAFOR.LIB except for MASTER, IA, CICERO, and DCHECK. 


\section{Cabling}

systems.

Specifications for cabling between Silena CICERO 8K and IBM PC (or compatible) computer

\section{"PC" type cables (for IBM PCXT and "clones")}

Connectors: female DB-25 to male DB-25.

Description: pins 5, 6, 8, and 20 jumpered at both ends.

Diagram:

DB-25

DB-25

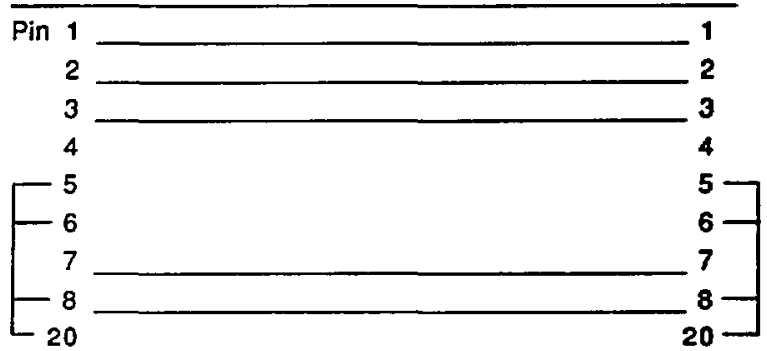

"AT" type cables (for IBM AT and most "laptops"

Connectors: female DB-9 to male DB-25.

Description: pins 1, 4, 6, and 8 jumpered at the DB-9 end; pins 1 and 7 and 5, 6, 8, and 20 jumpered at the $\mathrm{DB}-25$ end.

Diagram:

DB-9

DB-25

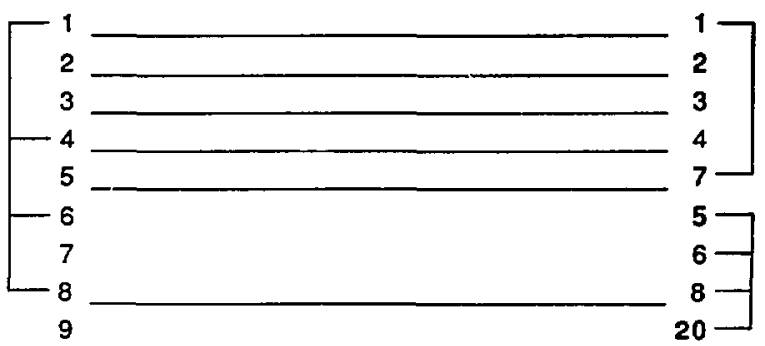

- Toshiba 1100/2100/3100/3200/5100. 


\section{Acknowledgments}

The data-transfer, data-analysis, and quality-assurance applications were developed jointly by the Lawrence Livermore National Laboratory Nuclear Chemistry Division, Livermore, Calif. 94551 USA and Compuchem, Inc., 30998 Huntwood Avenue, Suite 107 Hayward, Calif. 94544-7033 USA.

IAEA Plutonium Isotopics Analysis System for IBM PC and compatible computers developed for the Intemational Atomic Energy Agency by W. D. Ruhter, W. M. Buckley and R. Gunnink, Lawrence Livermore National Laboratory, under ISPO Task A.140 and by R. Fleming, Compuchem, Inc, under LLNL Personal Services Agreements 9107605 and 5541100.

Software Revision Level: 42, Reference Manual Revision: 4.2, release date: 24 July 1989. 